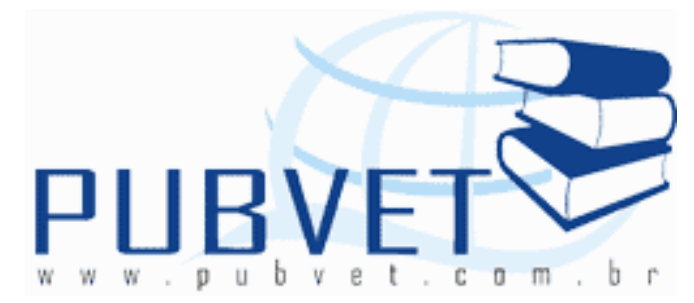

PUBVET, Publicações em Medicina Veterinária e Zootecnia.

\title{
Exemplos práticos do processo de autenticação de carnes e seus derivados
}

Luiz Carlos Vieira Júnior ${ }^{1}$, André Mendes Jorge ${ }^{2}$, Marco Aurélio Factori ${ }^{3}$, Marcela Buosi Matins ${ }^{1}$, Felipe Azevedo Ribeiro ${ }^{4}$, Edcarlos Oliveira Queiroz ${ }^{5}$

${ }^{1}$ Doutorando do Programa de Pós-Graduação em Zootecnia/UNESP/BotucatuSP;

${ }^{2}$ Professor do Departamento de Produção Animal/FMVZ/UNESP/Botucatu-SP;

${ }^{3}$ Pós-Doutorando do DMNA da FMVZ/UNESP/Botucatu-SP;

${ }^{4}$ Doutorando do Programa de Pós-Graduação em Zootecnia/UEM/Maringá-PR;

${ }^{5}$ Mestrando do Programa de Pós-Graduação em Zootecnia/UNESP/BotucatuSP.

\section{Resumo}

Há um aumento crescente na procura dos consumidores por informações dos fatores produtivos em herbívoros. Logo, especificação através de certificações de qualidade que garantam a credibilidade dos produtos se faz necessário. Uma das maneiras de buscar esta garantia se dá a partir da análise das características intrínseca do produto final ou dos animais. Isto se deve ao fato de que a natureza do alimento influência de forma significativa a composição dos tecidos e dos produtos de origem animal. Para tanto, componentes intrínsecos são transferidos para os tecidos a partir do metabolismo de dietas específicas. Alguns desses componentes podem ser utilizados como 
marcadores da dieta. Ainda, trata-se das principais metodologias aplicadas na discriminação de adulterações.

Palavras-chave: adulteração, elementos traçadores, ferramentas analíticas

\title{
Practical examples of the authentication process meat and its derivatives
}

\begin{abstract}
There is an increasing consumer demand for information on herbivore production factors. Therefore, specification through quality certifications to ensure the credibility of the products is necessary. One way to get the warranty starts from the analysis of the intrinsic characteristics of the final product or animal. The nature of the food strongly influences the composition of tissues and animal products. This is due to specific components that are directly transferred from the final product or are processed or the metabolism of specific diets. Some of these components may also be used as markers in the diet. Still, these are the main methodologies used in the discrimination of tampering.
\end{abstract}

Keywords: adulteration, tracer elements, analytical tools

\section{Introdução}

Hoje, muitos consumidores estão preocupados com a origem dos alimentos disponíveis ao consumo. A escolha de um produto em detrimento de outro pode refletir aspectos do estilo de vida (vegetarianismo e alimentos orgânicos), religião (por exemplo, ausência de carne de porco de algumas dietas), saúde (ausência de alérgenos). Nesta ocasião, a rotulagem assume importancia para informar e direcionar a escolha do consumidor, além disso, está ligada a promoção de um comércio justo. Embora os regulamentos consagrados na legislação nacional e internacional sustentam a obrigatoriedade das informações no rótulo, infelizmente, não são suficientes 
para impedir fraudes. Neste sentido, meios que promovam a autenticidade dos produtos é de suma importância.

Autenticação de alimentos é o processo pelo qual se legitima um produto que possui propriedades ou características idênticas a aquelas descritas nos rótulos, ou vice-versa. Para tanto, a disponibilidade de métodos analíticos que promovem garantia da autenticidade dos alimentos desempenha papel fundamental no funcionamento do comercio, como um todo.

Esta revisão fornece uma visão geral dos principais elementos traçadores e ferramentas analíticas utilizadas para a autenticação da carne e seus produtos.

\section{Identificação da origem da carne}

\section{Sexo}

È comum na descrição nos rótulos de cortes cárneos comercializados, a plavra "macho" informando o sexo do animal que fora abatido. Entretanto, a indicação "fêmea", de maneira geral dificilmente é encontrada. Lógicamente, as fêmeas de um rebanho são aproveitadas como matrizes nas fazendas, e desta forma, o abate desta classe animal é relativamente pequena quando comparada aos machos. Porém, no Brasil a negociação de vacas de descarte e novillhas é usualmente praticada, principalmente quando produtores conseguem agregar valor ou até mesmo fixar os mesmos preços da arroba paga aos machos, para novilhas que apresentem carcaça de qualidade superior.

Análise dos hormônios sexuais esecíficos é um métodos convencional usado para determinar o sexo dos animais a partir de um corte cárneo (Zeleny e Schimmel, 2002).

A metodologia normalmente utilizada para à avaliação dos hormônios sexuais bovinos e consequente determinação do sexo é a reação em cadeia da polimerase (PCR), que toma por base regiões do DNA que diferem entre indivíduos do sexo masculino e feminino (fonte). Normalmente na PCR a amplificação dos genes ZFX e ZFY têm sido empregada para determinar o sexo 
de bovinos Zinovieva et al, 1995), suínos (Lockley et al., 1997) ovinos e caprinos (Aasen \& Medrano, 1990).

\section{Raça}

O presunto ibérico, caracterizada pelo seu sabor intenso, é uns dos produtos cárneos mais apreciados da Espanha (Bote López, 1998). Três fatores principais são associados ao elevado preço de mercado deste produto: origem racial das matérias-primas (porco ibérico), a extenso período de acabamento baseado na utilização de pastagens (montanera), além do tradicional método de maturação, por cerca de 12-24 meses. Estes fatores coopeeram para que a oferta de tal produto seja menor que a demanda.

O termo "porco ibérico" é um agrupamento racial para os porcos nativo da Península Ibérica (Dieguez, 1992). O cruzamento Industrial entre suínos da raça Duroc e Ibérica tornaram-se comuns, pelo fato de promover uma melhoria na taxa de crescimento, da conversão alimentar e na proporção de carne magra na carcaça. A atual legislação espanhola (Boletin Oficial del Estado, de 2001, 2003) permite até 50\% da raça Duroc nos animais utilizados para produzir Presuntos ibéricos. As diferenças de preços elevados (5-10 vezes) entre Presunto ibérico seco curado e presunto derivado de outras raças de suínos. Isto, certamente serve de incentivo a ações fraudulentas nos rótulo deste tipo de presunto, resultando em impacto negativo sobre o produto regulamentado. Portanto, é conveniente análises de modo a determinar existências de fraudes contra o consumidor e até que ponto isso ocorre.

\section{Carne Orgânica vs Convencional}

Uma das restrições da produção de carne orgânica é o uso de medicamentos veterinários e as regras ditam como e quando tais drogas podem ser utilizadas. A identificação da utilização indevida de tetraciclinas pode colaborar a verificar se as carcaças dos animais estão em conformidade com as regras do sistema de produção orgânica. 
Nesta ocasião, a metodologia de microscopia de fluorescência (Kelly et al., 2006) pode estimar a dose de tetraciclina administradas em suínos e frango. Porém, esta análise não é conclusiva, pois, a ausência de tetraciclinas não garante que um produto seja considerado orgânico.

Outra estratégia analítica pode ter como base a composição isotópica dos tecidos animais. Estudos puderam afirmar diferenças entre carne bovina irlandesa produzida sobre premissas de sistema orgânico daquele convencional, utilizando a técnica de espectrometria de massa dos isótopos de carbono, nitrogênio e enxofre (Schmidt et al., 2005).

\section{Adulteração de Espécies e Tecidos}

Fraudes de substituição de carne pode envolver espécies e tecidos. No que tange a adulteração de espécies, cita-se como exemplo, o consumo de carne suína. Na visão de algumas religiões como o islamismo e o judaísmo, esta questão é de extrema seriedade.

No Islãmismo, alimentos que tenham em sua composição ingredientes derivados da espécie suína é inaceitável ou "Haram". A palavra árabe Halal significa "permitido", sendo seu antônimo Haram. No versículo $3^{\circ}$ da $5^{a}$ surata, o Alcorão prescreve: Estão-vos vedados: a carniça, o sangue, a carne de suíno e tudo o que tenha sido sacrificado com a invocação de outro nome que não seja o de Alá.

Portanto, o controle rigoroso da autenticidade das matérias-primas a serem utilizadas para a preparação industrial de alimentos e na detecção de espécies animais em produtos alimentares é necessário. Isto é especialmente crucial para Halal. Haja vista, que seria fatal um único pedaço de toucinho de porco, destinado à linha tradicional de embutidos.

Vale destacar, que o mercado de produtos certificados atende cerca de 1,3 bilhões de mulçumanos no mundo, e de outros cidadãos que optaram se alimentar de produtos certificados pelo método Halal (Valente, 2009).

Na determinação das espécies, a análise de DNA e proteínas são práticas comuns. Deteç̧ão de proteínas tem sido tradicionalmente o método mais 
adequado para a determinação de espécies animais. Além disso, quando em comparação com as proteínas, DNA tem uma maior estabilidade térmica, está presente em a maioria das células e, potencialmente, permite que as informações idênticas às ser obtidos do mesmo animal, independentemente de tecido de origem (Lockley e Bardsley, 2000).

Ademais, a substituição fraudulenta de um tecido determinado por outro (colágeno e vísceras) também pode ser rentável para a indústria alimentar. Entretanto, é permissível a partir do aminoácido natural, 4 - hidroxiprolina (Hyp), um componente presente (na proporção de $8 \%$ ) no colágeno, determinar tal adulteração (Etherington e Sims, 1981). Diferentes quantidades de hyp em partes diferentes da carne pode ser usada para calcular o teor de colágeno em carnes e produtos derivados (Anon, 2008). O método de referência da UE para quantificação dos hyp (Anon, 1978) é baseada em um simples método de espectroscopia.

\section{Gordura Vegetal e Animal}

Em produtos de carne, gordura vegetal pode substituir de forma ilícita a gordura animal. No entanto, gordura vegetal geralmente contém fitoesteróis como estigmasterol e $\beta$-sitosterol, que estão ausentes em gordura animal. Assim, oocorrência de estigmasterol e $\beta$-sitosterol em produtos cárneos é indicativos da presença de gordura vegetal (Ballin, 2010).

Ainda, a inclusão indevida de gordura animal de uma espécie pode ser utilizada para substituir a gordura animal de outra espécie. No entanto, ambos gordura animal e gordura vegetal contêm quantidades e especificidade de ácidos graxos (Precht, 1992a).

Todavia, técnicas como: a HPLC (Nair et al., 2006), GC-MS (Szucs et al., 2006), e atmosférica pressão fotoionização (APPI) LC-MS/MS (Lembcke et al., 2005) podem ser aplicadas na deteç̧ão de uma possível adulteração. 


\section{Proteína vegetal, animal e compostos orgânicos}

A proteína vegetal oriunda da soja, devido sua disponibilidade e preço atrativo, tem sido considerada uma das proteínas mais comumente usadas na substituição da proteína animal. A proteína de soja pode ser detectado por ELISA métodos (Gonzalez-Cordova et al, 1998;. Koppelman et al, 2004). Porém, a detecção da proteína pode ser impossível se sofrerem degradação ou forem severamente alteradas durante o processamento da carne.

Além da substituição por vegetais e proteínas animais, melamina e uréia têm sido utilizadas em substituição fraudulenta de proteína (Frick et al, 2009; . Sivaraman, 2007). Melamina e uréia contém $67 \%$ e $43 \%$ de nitrogênio, em massa, respectivamente, em comparação com a proteína da carne que contém cerca de $16 \%$ de nitrogênio, em massa (Benedict, 1987). Kjeldahl de análise (Wiles, Gray e kissling, 1998) ou técnicas de combustão, tais como Dumas são frequentemente usados para medir a teor de nitrogênio total, que é então convertido em proteína.

No entanto, nem Kjeldahl nem Dumas são capazes de diferenciar entre os átomos de nitrogênio derivados de compostos de proteína ou químicos. Assim, a melamina e uréia podem fraudar frações da proteína da carne sem serem detectadas através destas análises. Porém, métodos que se concentram nos perfis de proteínas para detecção qualitativa de uma variedade de carnes, que incluem carne bovina, suína, e frango a partir de produtos crus e cozinhados foram publicados por Ashoor et al, (1988) e Chou et al, (2007).

\section{Considerações finais}

Conforme foi relatado, há inúmeras ocorrências de adulterações na carne e seus derivados. Apesar de metodologias analíticas direcionadas a detectar tais adulterações, ainda a capacidade destas análises devem ser melhor estudadas, pois os resultados ainda são incipientes. Portanto, metodologias e equipamentos acessíveis são necessários de modo que estas análises possam ser executadas de maneira rotineira. 


\section{Referências}

AASEN, E., \& MEDRANO, J. F. (1990). Amplification of the Zfy and Zfx genes for sex identification in humans, cattle, sheep and goats. Nature Biotechnology, 8(12), 1279-1281.

ANON (1978). Meat and meat products-Determination of $L(-)$-hydroxyproline content (Reference method). International Organization for Standardization, 3496.

ANON (2008). Commission Regulation (EC) No 903/2008 of 17 September 2008 on special conditions for granting export refunds on certain pigmeat products. L249. Official Journal of the European Union, 3-8.

ASHOOR, S. H., MONTE, W. C., \& STILES, P. G. (1988). Liquid chromatographic identification of meats. Journal-Association of Official Analytical Chemists, 71(2), 397-403.

BALLIN. N.Z.. Authentication of meat and meat products. Meat Science 86 (2010) 577-587.

BOLETIN OFICIAL DEL ESTADO, (2003). Orden APA/213/2003, de 10 de febrero por la que se establecen normas de desarrollo del Real Decreto 1083/2001, de 5 de octubre, por el que se aprueba la norma de calidad para el jamo'n ibe 'rico, paleta ibe 'rica y can ª de lomo ibe 'rico elaborados em Espan a. Boletin Oficial Del Estado .O.E., 36, pp. 5305-5310.

DIEGUEZ, E., (1992). Historia, evolución y situación actual del cerdo ibérico. pg 9-35. In EI Cerdo Ibérico, la naturaleza, la dehesa. Ministerio de Agricultura, Pesca y Alimentacio 'n, Madrid.

ETHERINGTON, D. J., \& SIMS, T. J. Detection and estimation of collagen. Journal of the Science of Food and Agriculture, 32(6), 539-546. 1981.

FRICK, G., DUBOIS, S., CHAUBERT, C., \& AMPUERO, S. Identification by microscopy and MSbased electronic nose of a fraudulent addition to maize gluten. Biotechnology, Agronomy, Society and Environment, 13(S), 45-50. 2009.

GONZALEZ-CORDOVA, A. F., CALDERON DE LA BARCA, A. M., COTA,M., \& VALLEJO-CORDOBA, B. Deteccion inmunoquimica de la adulteracion de chorizo de cerdo con proteinas de soja: Immunochemical detection of fraudulent adulteration of pork chorizo (sausage) with soy protein. Food Science and Technology International, 4(4), 257-262. 1998.

KELLY, M., TARBIN, J. A., ASHWIN, H., \& SHARMAN, M. Verification of compliance with organicmeat production standards by detection of permitted and nonpermitted uses of veterinary medicines (tetracycline antibiotics). Journal of Agricultural and Food Chemistry, 54(4), 1523-1529. 2006.

KOPPELMAN, S. J., LAKEMOND, C. M., VLOOSWIJK, R., \& HEFLE, S. L. Detection of soy proteins in processed foods: Literature overview and new experimental work. Journal of AOAC International, 87(6), 1398-1407. 2004.

LEMBCKE, J., CEGLAREK, U., FIEDLER, G. M., BAUMANN, S., LEICHTLE, A., \& THIERY, J. Rapid quantification of free and esterified phytosterols in human serum using APPILC- MS/MS. Journal of Lipid Research, 46(1), 21-26. 2005.

LOCKLEY, A. K., BRUCE, J. S., FRANKLIN, S. J., \& BARDSLEY, R. G. Simultaneous detection of a sex-specific sequence and the Ryr1 point mutation in porcine genomic DNA. Meat Science, 45(4), 485-490. 1997.

LOCKLEY, A. K., \& BARDSLEY, R. G. DNA-based methods for food authentication. Trends in Food Science \& Technology, 11(2), 67-77. 2000.

LÓPEZ-BOTE, C. J. Sustained utilization of the Iberian pig breed. Meat Science, 49(Suppl.), S17-S27. 1998.

NAIR, V. D., KANFER, I., \& HOOGMARTENS, J. Determination of stigmasterol, betasitosterol and stigmastanol in oral dosage forms using high performance liquid chromatography with 
evaporative light scattering detection. Journal of Pharmaceutical and Biomedical Analysis, 41(3), 731-737. 2006.

SIVARAMAN, A. Melamine in pet food, wheat gluten from China. FDA. www.reuters.com/article/domesticNews/idUSWEN594320070330. Acesso em: 30 de setembro de 2007.

SCHMIDT, O., QUILTER, J. M., BAHAR, B., MOLONEY, A. P., SCRIMGEOUR, C. M., BEGLEY, I. $\mathrm{S}$., et al. Inferring the origin and dietary history of beef from $\mathrm{C}, \mathrm{N}$ and $\mathrm{S}$ stable isotope ratio analysis. Food Chemistry, 91(3), 545-549. 2005.

SZUCS, S., SARVARY, A., CAIN, T., \& ADANY, R. Method validation for the simultaneous determination of fecal sterols in surface waters by gas chromatography- mass spectrometry. Journal of Chromatographic Science, 44(2), 70-76. 2006.

WILES, P. G., GRAY, I. K., \& KISSLING, R. C. Routine analysis of proteins by Kjeldahl and Dumas methods: Review and interlaboratory study using dairy products. Journal of AOAC International, 81(3), 620-632. 1998.

ZELENY, R., \& SCHIMMEL, H. (2002). Sexing of beef-A survey of possible methods. Meat Science, 60(1), 69-75. 2002. 